\title{
Impact of Extraperitoneal Dioxyde Carbon Insufflation on Respiratory Function in Anesthetized Adults: A Preliminary Study Using Electrical Impedance Tomography and Wash-out/Wash-in Technic
}

\author{
Julien Bordes ${ }^{1,3}$; Cecilia Mazzeo ${ }^{1}$; Philippe Gourtobe ${ }^{1}$; Pierre Julien Cungi ${ }^{1}$; Francois An- \\ tonini ${ }^{2}$; Stephane Bourgoin ${ }^{3}$; Eric Kaiser ${ }^{1}$ \\ ${ }^{1}$ Department of Anesthesia and intensive care, Sainte Anne Military Teaching Hospital, Toulon, France \\ ${ }^{2}$ Department of Anesthesia and intensive care, Nord Hospital, Aix Marseille University Marseille, France \\ ${ }^{3}$ Department of Visceral Surgery, Sainte Anne Military Teaching Hospital, Toulon, France \\ ${ }^{*}$ Corresponding author: Julien Bordes, Department of Anesthesia and intensive care, Sainte Anne Military Teaching Hospital, Sainte Anne Boulevard, 83000 Toulon, France. Tel: +33- \\ 483162385, Fax: +33-483162743, E-mail: bordes.julien@neuf.fr
}

Received: August 17, 2014; Revised: September 15, 2014; Accepted: November 17, 2014

\begin{abstract}
Background: Extraperitoneal laparoscopy has become a common technique for many surgical procedures, especially for inguinal hernia surgery. Investigations of physiological changes occurring during extraperitoneal carbon dioxide $\left(\mathrm{CO}_{2}\right)$ insufflation mostly focused on blood gas changes. To date, the impact of extraperitoneal $\mathrm{CO}_{2}$ insufflation on respiratory mechanics remains unknown, whereas changes in respiratory mechanics have been extensively studied in intraperitoneal insufflation.

Objectives: The aim of this study was to investigate the effects of extraperitoneal $\mathrm{CO}_{2}$ insufflation on respiratory mechanics.

Patients and Methods: A prospective and observational study was performed on nine patients undergoing laparoscopic inguinal hernia repair. Anesthetic management and intraoperative care were standardized. All patients were mechanically ventilated with a tidal volume of $8 \mathrm{~mL} / \mathrm{kg}$ using an Engström Carestation ventilator (GE Healthcare). Ventilation distribution was assessed by electrical impedance tomography (EIT). End-expiratory lung volume (EELV) was measured by a nitrogen wash-out/wash-in method. Ventilation distribution, EELV, ventilator pressures and hemodynamic parameters were assessed before extraperitoneal insufflation, and during insufflation with a PEEP of $0 \mathrm{CmH}_{2} \mathrm{O}, 5 \mathrm{cmH}_{2} \mathrm{O}$ and of $10 \mathrm{CmH}_{2} \mathrm{O}$.

Results: EELV and thoracopulmonary compliance were significantly decreased after extraperitoneal insufflation. Ventilation distribution was significantly higher in ventral lung regions during general anesthesia and was not modified after insufflation. A $10 \mathrm{cmH}_{2} \mathrm{O} \mathrm{PEEP}$ application resulted in a significant increase in EELV, and a shift of ventilation toward the dorsal lung regions.

Conclusions: Extraperitoneal insufflation decreased EELV and thoracopulmonary compliance. Application of a $10 \mathrm{cmH}_{2} \mathrm{O} \mathrm{PEEP}_{\text {increased }}$ EELV and homogenized ventilation distribution. This preliminary clinical study showed that extraperitoneal insufflation worsened respiratory mechanics, which may justify further investigations to evaluate the clinical impact.
\end{abstract}

Keywords:Insufflation; Respiratory Mechanics; Anesthesia; Tomography; Ventilation

\section{Background}

Extraperitoneal laparoscopy has become a common technique for many surgical procedures, especially inguinal hernia surgery. In this setting, it has been shown that laparoscopic technique has less chronic postoperative pain and numbness, fast return to normal activities and decreased incidence of wound infection and hematoma (1). We observed in our clinical practice that the advent of laparoscopy has resulted in extended indications, as in elderly patients with respiratory disease. Investigations of physiological changes occurring during extraperitoneal carbon dioxide $\left(\mathrm{CO}_{2}\right)$ insufflation mostly focused on blood gas changes. Extraperitoneal insufflation has been reported to increase arterial $\mathrm{pCO}_{2}$, with data suggesting a more rapid and greater total increase in End-tidal $\mathrm{CO}_{2}\left(\mathrm{ETCO}_{2}\right)$ during extraperitoneal insufflation than pneumoperitoneum (2-4). To date, the impact of extraperitoneal $\mathrm{CO}_{2}$ insufflation on respiratory mechanics remains unknown, whereas changes in respiratory mechanics have been extensively studied in intraperitoneal insufflation (5-7).

\section{Objectives}

The purpose of our study was to investigate the effects of extraperitoneal $\mathrm{CO}_{2}$ insufflation on respiratory mechanics using two bedside techniques, the electrical impedance tomography (EIT) and wash-out/wash-in technique.

\section{Patients and Methods}

The study was approved by the Ethics Committee of the Sainte Anne military teaching Hospital. A written informed consent was obtained from patients. Patients aged 18 years and older scheduled for extraperitoneal

Copyright (C) 2015, Iranian Society of Regional Anesthesia and Pain Medicine(ISRAPM). This is an open-access article distributed under the terms of the Creative Commons Attribution-NonCommercial 4.0 International License (http://creativecommons.org/licenses/by-nc/4.0/) which permits copy and redistribute the material just in noncommercial usages, provided the original work is properly cited. 
laparoscopic surgery were recruited from October to November 2013. Patients with a body mass index $>35 \mathrm{~kg} /$ $\mathrm{m}^{2}$, preexisting cardiac disease or pathologic lung function requiring noninvasive ventilation or oxygen therapy were excluded. Anesthetic management was standardized as follows. On their arrival in the operating room, standard monitoring device (electrocardiogram, pulse oximeter, and noninvasive arterial pressure [Intellivue MP40 monitor, Philips]) was applied. The level of anesthesia was monitored by bispectral index monitoring. Patients were given a $10 \mathrm{~mL} / \mathrm{kg}$ of crystalloid solution intravenously before the induction. Preoxygenation was performed in pressure support ventilation (Inspiratory pressure of $8 \mathrm{cmH}_{2} \mathrm{O}$, and PEEP of $4 \mathrm{cmH}_{2} \mathrm{O}$ ). Anesthesia was induced and maintained with propofol, remifentanil or sufentanil and atracurium. Muscle relaxation was controlled by monitoring the TOF ratio. After induction, the trachea was intubated. Immediately after intubation, patients were mechanically ventilated (Engstrom Carestation ventilator; Datex-Ohmeda, General Electric Healthcare) in volume-controlled mode with a tidal volume (TV) of $8 \mathrm{~mL} / \mathrm{kg}$ ideal body weight. The respiratory rate was adjusted to an end-tidal carbon dioxide concentration $\left(\mathrm{EtCO}_{2}\right)$ between 35 and 40 $\mathrm{mmHg}$. The inspiratory flow was settled to an inspiratory/expiratory ratio of $1 / 2$. No PEEP was initially added. The inspiratory oxygen fraction $\left(\mathrm{FiO}_{2}\right)$ was 0.5 . An inspiratory pause of half a second was settled to monitor plateau pressure. Absence of intrinsic PEEP was evaluated by means of end-expiratory occlusion. Extraperitoneal insufflation was generated by insufflating carbon dioxide with pressure maintained at $10 \mathrm{mmHg}$.

\subsection{Study Protocol}

A schema of the protocol is provided in Figure 1. Anesthesia induction and study procedures were performed in supine position. Measurements were performed during baseline conditions and at three time points as described below:

-baseline conditions: after induction, patient was intubated and mechanically ventilated. Tidal volume was 8 $\mathrm{mL} / \mathrm{kg}$ ideal body weight, respiratory rate was adjusted to EtCO2 value between 35 and 40 mmHg; FIO2 was 50\%. No PEEP was added;

-time point 1: 5 minutes after extraperitoneal insufflation with no PEEP;

-time point 2: during insufflation, 5 minutes after application of a PEEP $5 \mathrm{CmH}_{2} \mathrm{O}$;

-time point 3: during insufflation, 5 minutes after application of a PEEP $10 \mathrm{cmH}_{2} \mathrm{O}$.

At baseline and at each measurement time point, heart rate, systolic and diastolic arterial pressure, $\mathrm{EtCO}_{2}$ value, BIS index, peak airway pressure and plateau pressure were recorded.

\subsection{Ventilation Distribution Measurements}

Ventilation distribution was assessed by EIT (Figure 2). EIT uses the electrical conductivity of chest to generate cross sectional images of lung inferred from surface electrical measurements realized by a 16 electrodes belt

Figure 1. The Study Protocol

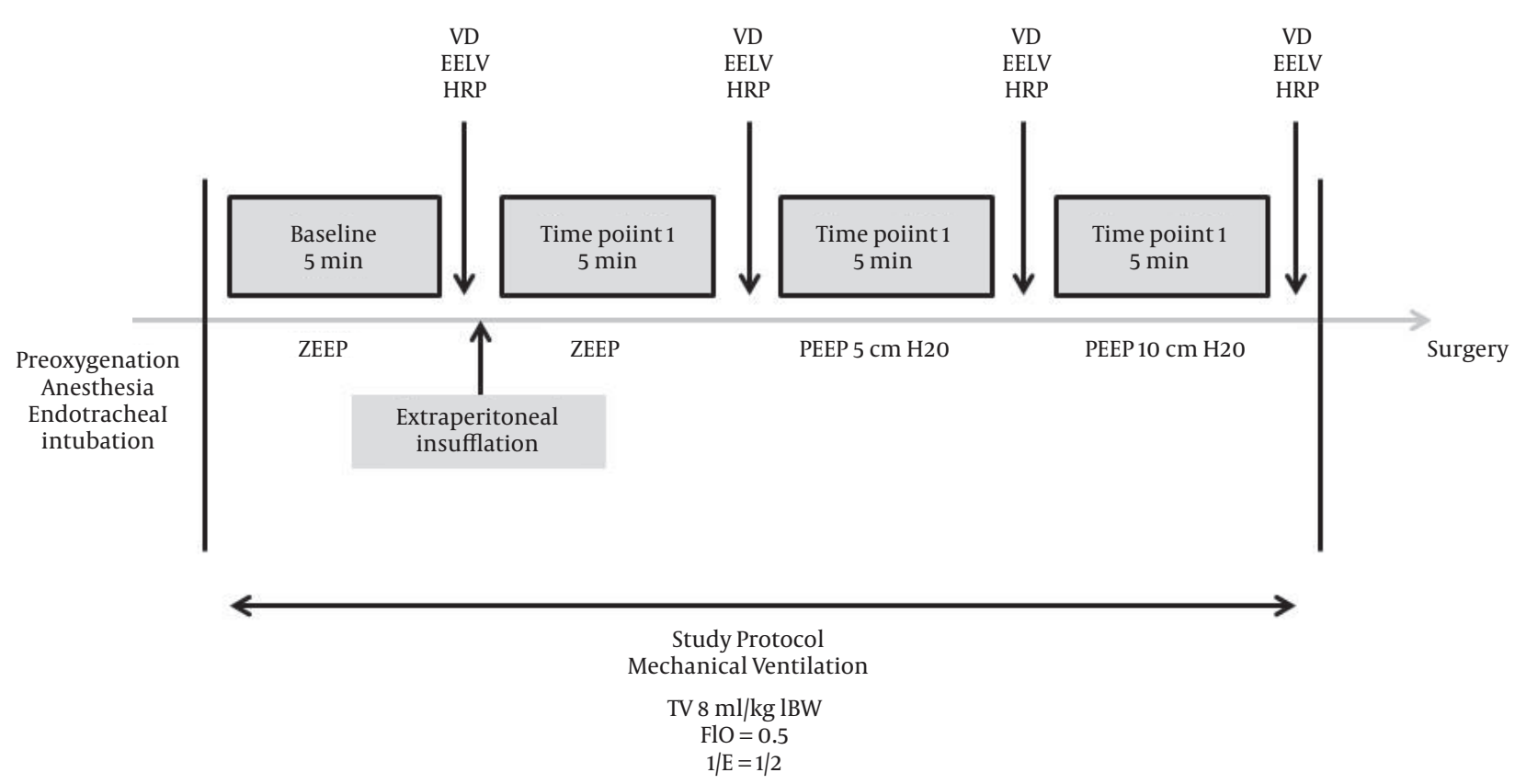

VD, ventilation distribution; EELV, end-expiratory lung volume; HRP, hemodynamic and respiratory parameters. 
Bordes J et al.

placed to the skin. A few milliamperes current is applied across two electrodes; all other electrodes are used to measure resulting voltage. In biological tissue, conductivity varies between tissues depending on factors as air content. The changes in impedance are correlated to changes in air content. We used the Pulmovista $₫ 500$ tomograph (Drager medical) to perform EIT measurements. The electrodes belt was placed around the patients' chest between the 4 th and 6 th intercostal space. The Pulmovista $₫ 500$ tomograph measures impedance changes referring to an initial reference data set in real time. It generates a cross sectional image of the lung that can be divided in four regions of interest (ROI), each covering $25 \%$ of the ventrodorsal diameter. Impedance changes can be analyzed by ROI. To evaluate ventilation distribution, the number calculated per ROI is the sum of impedance changes in this ROI in relation to the sum of impedance changes of the whole EIT image. For instance, a number of $51 \%$ in ROI 1 indicates that $51 \%$ of the tidal volume variation takes part in this ROI (Figure 2). An increase in the fractional tidal variation per ROI indicates a redistribution of ventilation toward this ROI. In our study, ROI 1 and 2 represented ventral lung areas; whereas, ROI 3 and 4 represented dorsal lung areas.

\subsection{End-Expiratory Lung Volume Measurements}

End-expiratory lung volume (EELV) was assessed by a built-in modified nitrogen wash-out/wash-in technique. It was measured twice using an automated procedure available on the ventilator (GE Healthcare). EELV measurements reflect the amount of gas in the lungs and require $\mathrm{FIO}_{2}$ step of 0.1 as previously described $(8,9)$.

\subsection{Thoracopulmonary Compliance Measure- ments}

Thoracopulmonary compliance was calculated as $\Delta$ Paw/TV, where $\Delta$ Paw is the difference between plateau pressure and end-expiratory airway pressure, and TV is the tidal volume.

\subsection{Statistical Analyses}

Statistical analysis was performed using XLSTATS software (Addinsoft, Paris, France). Descriptive measures were used to present patients' characteristics. No a priori power analysis was conducted, because we did not know the exact effect size that we would see. EELV and respiratory pressure changes during the study were compared using the Friedman two-way analysis of variance test. Ventilation distribution between the left and right lungs was compared at baseline and time point 1 using a Mann and Whitney test. Ventilation distribution changes throughout the study were compared for left and right lungs using the Friedman two-way analysis of variance test. The Friedman two-way analysis of variance test was used to compare heart rate (HR), systolic blood pressure
(SBP), diastolic blood pressure (DBP), $\mathrm{EtCO}_{2}$ and BIS index during the study. A P value $<0.05$ was required to reject the null hypothesis.

\section{Results}

Nine consecutive adult patients undergoing laparoscopic hernia inguinal repair were enrolled. There were eight male and one female. The mean age was of $61 \pm 22$ years. The mean body mass index was $24.8 \pm 3.6 \mathrm{~kg} / \mathrm{m}^{2}$. Patients' characteristics are provided in Table 1 . No relevant clinical complications occurred during the operation. According to the protocol, respiratory rate, tidal volume and flow rate were not changed during the investigation.

Figure 2. EIT Image Was Divided Into Four Quadrants or "Regions of Interest" (ROI)

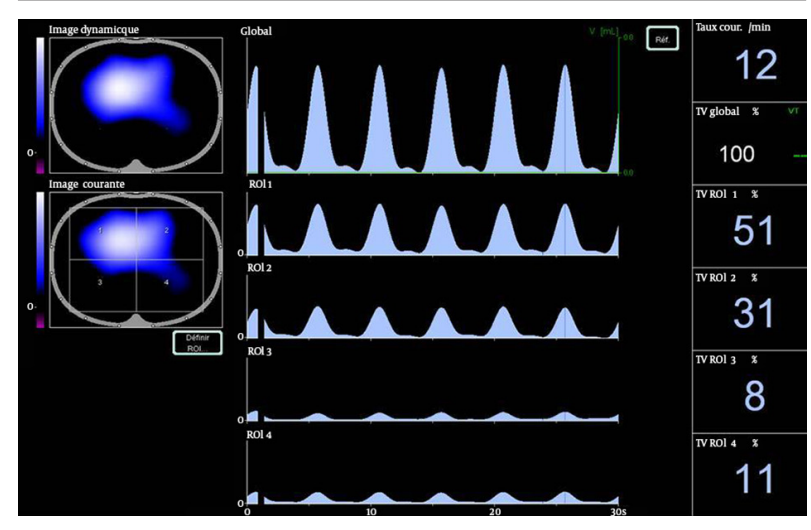

In our study, ROI1 and 2 were ventral regions; ROI 3 and 4 were dorsal regions. In this patient, $82 \%$ of tidal volume variation was distributed in ventral region.

\begin{tabular}{lc}
\hline Table 1. Patients' Characteristics ${ }^{\text {a }}$ & \\
\hline & Results \\
\hline Gender & \\
\hline Male & 1 \\
\hline Female & $61 \pm 22$ \\
\hline Age, $\mathbf{~}$ & $74 \pm 11$ \\
\hline Weight, kg & $173 \pm 10$ \\
\hline Height, cm & $24.8 \pm 3.6$ \\
\hline BMI, kg/m ${ }^{2}$ & \\
\hline ASA classification, no & 2 \\
\hline 1 & 6 \\
\hline 2 & 1 \\
\hline 3 & \\
\hline Patients comorbidities, No. & 3 \\
\hline Smoker & 4 \\
\hline Arterial hypertension & 1 \\
\hline Coronary disease & \\
\hline Laparoscopic surgery, No. & 9 \\
\hline Inguinal hernia repair & \\
\hline All data are presented as Mean \pm SD unless otherwise specified. \\
\hline
\end{tabular}


Bordes J et al.

\begin{tabular}{|c|c|c|c|c|}
\hline & Baseline & Time Point 1 & Time Point 2 & Time Point 3 \\
\hline ROI 1 et 2 ventral region, $\%$ & $74.5 \pm 11.7$ & $74.5 \pm 14.3$ & $72.4 \pm 13.4$ & $61.5 \pm 19.5$ \\
\hline ROI 3 et 4 dorsal region, \% & $20.7 \pm 11.3$ & $23.1 \pm 13.8$ & $24.5 \pm 12.9$ & $34.8 \pm 18.9$ \\
\hline \multicolumn{5}{|c|}{${ }^{\mathrm{a}}$ All data are presented as Mean $\pm \mathrm{SD}$. } \\
\hline \multicolumn{5}{|c|}{ Table 3. Respiratory and Hemodynamic Data a, b } \\
\hline & Baseline & $\begin{array}{c}\text { Time Pointe } \\
\text { 1Insufflation PEEP o }\end{array}$ & $\begin{array}{c}\text { Time Point } 2 \\
\text { Insufflation PEEP } 5\end{array}$ & $\begin{array}{c}\text { Time Point } 3 \\
\text { Insufflation PEEP } 10\end{array}$ \\
\hline $\begin{array}{l}\text { Peak airway pressure, } \\
\mathrm{cmH}_{2} \mathrm{O}\end{array}$ & $18.9 \pm 1.8$ & $21.5 \pm 2.5$ & $24.4 \pm 2.2^{C}$ & $29.3 \pm 2.7^{C}$ \\
\hline Plateau pressure, $\mathrm{cm} \mathrm{H}_{2} \mathrm{O}$ & $10.6 \pm 1.8$ & $13.1 \pm 1.9$ & $16.5 \pm 1.7^{C}$ & $21.4 \pm 2^{C}$ \\
\hline $\begin{array}{l}\text { Thoracopulmonary com- } \\
\text { pliance, } \mathrm{mL} / \mathrm{cmH}_{2} \mathrm{O}\end{array}$ & $49.5 \pm 6.3$ & $40.1 \pm 5^{c}$ & $45.6 \pm 6.5$ & $46.8 \pm 9.7^{d}$ \\
\hline EELV, mL & $2115 \pm 635$ & $1716 \pm 444^{\mathrm{C}}$ & $1898 \pm 542$ & $2253 \pm 616^{d}$ \\
\hline $\mathrm{EtCO}_{2}, \mathrm{mmHg}$ & $33.5 \pm 2.4$ & $34.2 \pm 4.7$ & $37 \pm 5.7$ & $38.7 \pm 5.1^{\mathrm{C}}$ \\
\hline SAP, mmHg & $109 \pm 12$ & $136 \pm 30^{c}$ & $136 \pm 23^{c}$ & $134 \pm 23$ \\
\hline DAP, mmHg & $65 \pm 10$ & $80 \pm 22$ & $78 \pm 20$ & $76 \pm 11$ \\
\hline Heart rate, /min & $70 \pm 10$ & $68 \pm 11$ & $65 \pm 9$ & $64 \pm 13$ \\
\hline BIS index & $41 \pm 11$ & $36 \pm 9$ & $36 \pm 10$ & $32 \pm 8^{C}$ \\
\hline \multicolumn{5}{|c|}{$\begin{array}{l}\text { a Abbreviations: EELV, end expiratory lung volume; SAP, systolic arterial pressure; DAP, diastolic arterial pressure. } \\
\text { b All data are presented as Mean } \pm \text { SD. } \\
\text { c versus baseline } \mathrm{P}<0.05 \text {. } \\
\text { d versus time point } 1 \mathrm{P}<0.05 \text {. }\end{array}$} \\
\hline
\end{tabular}

\subsection{Ventilation Distribution at Baseline}

At baseline conditions, tidal volume was mostly distributed to ventral lung regions $(74.5 \% \pm 11.7$ in ventral regions versus $20.7 \% \pm 11.3$ in dorsal regions, $\mathrm{P}=0.0004$ ) (Table 2 ).

\subsection{Effects of Extraperitoneal Insufflation}

After insufflation, ventilation distribution was not modified $(74.5 \% \pm 14.3$ in ventral regions at time point 1 versus $74.5 \% \pm 11.7$ at baseline, $\mathrm{P}=0.9)$. The difference of ventilation distribution remained significant between the ventral and dorsal regions $(74.5 \% \pm 14.3$ versus $23.2 \% \pm 13.8 \mathrm{P}$ $=0.0004)$. Extraperitoneal insufflation was associated with a significant decrease in EELV measured by nitrogen wash-out/wash-in technique from $2115 \mathrm{~mL} \pm 635$ to $1716 \mathrm{~mL}$ $\pm 444(\mathrm{P}=0.0018)$ (Table 3$)$, and a significant decrease in thoracopulmonary compliance from $49.5 \pm 6.3$ to $40.1 \pm$ $5 \mathrm{~mL} / \mathrm{cmH}_{2} \mathrm{O}(\mathrm{P}=0.002)$. Insufflation did not modify plateau pressure values $\left(13.1 \mathrm{cmH}_{2} \mathrm{O} \pm 1.9\right.$ versus $10.6 \pm 1.8, \mathrm{P}=$ $0.35)$, nor peak pressure values $(21.5 \pm 2.5$ versus $18.8 \pm 1.8$, $\mathrm{P}=0.354)$.

\subsection{Effects of PEEP Application}

A PEEP $5 \mathrm{cmH}_{2} \mathrm{O}$ did not change ventral shift of ventilation. A lower ventral shift of ventilation with a PEEP 10
$\mathrm{CmH}_{2} \mathrm{O}$ was observed $(61.5 \% \pm 19.5$ at time point 3 versus $74.5 \pm 14.3$ at time point $1, \mathrm{P}=0.008$ ) (Table 2 ). A PEEP 5 $\mathrm{CmH}_{2} \mathrm{O}$ did not significantly change EELV and thoracopulmonary compliance (Table 3 ). Compared with ZEEP after insufflation was induced, PEEP $10 \mathrm{cmH} 20$ significantly increased EELV from $1716 \mathrm{~mL} \pm 444,4$ to $2253 \mathrm{~mL} \pm 616$ (P $=0.006)$, and thoracopulmonary compliance from $40.1 \pm$ 5.1 to $46.8 \pm 9.6(\mathrm{P}=0.031)$.

\subsection{Changes in Hemodynamic and Respiratory Pa- rameters During the Study (Table 3)}

$\mathrm{EtCO}_{2}$ was significantly increased at time point 3 versus baseline (38.7 \pm 5 versus $33.5 \pm 2.4, \mathrm{P}=0.008$ ). Extraperitoneal insufflation was associated with a significant increase in SAP (137.7 \pm 30 versus $109.9 \pm 12, \mathrm{P}=0.014)$, but DAP did not change significantly $(80.8 \pm 22$ versus $65 \pm$ $9.9, P=0.052)$. Heart rate did not change significantly throughout the study.

BIS index value at time point 3 was significantly lower that of baseline (31.6 \pm 8 versus $41.2 \pm 11.9, \mathrm{P}=0.014)$.

\section{Discussion}

The present study demonstrated that extraperitoneal $\mathrm{CO}_{2}$ insufflation was associated with a significant 
Bordes J et al.

decrease in FRC and thoracopulmonary compliance. Mechanical ventilation and general anesthesia were associated with a ventral distribution of tidal volume. Application of a 10- $\mathrm{cmH}_{2} \mathrm{O}$ PEEP led to a significant increase in FRC, thoracopulmonary compliance and homogenization of tidal volume distribution. Extraperitoneal laparoscopy has become a common surgical procedure, especially to inguinal hernia surgery. It has been shown that laparoscopic technique had less chronic postoperative pain, fast return to normal activities and decreased incidence of wound infection and hematoma (1). The advent of laparoscopy has resulted in extended indications, as in elderly patients with cardiorespiratory disease. However, the investigations on the respiratory effects of $\mathrm{CO}_{2}$ insufflation mostly focused on intraperitoneal insufflation. In this setting, it has been demonstrated in a CT-scan study that pneumoperitoneum by increasing abdominal pressure induced a mechanical compression and a cranial shift of the diaphragm between 1 and $3 \mathrm{~cm}$. Besides, this study showed that pneumoperitoneum induced a mean increase of atelectasis volume of $66 \%$ (7). These effects promote alveolar collapse and atelectasis, which worsens respiratory mechanics resulting in decreased end-expiratory lung volume and thoracopulmonary compliance $(2,5,6,10-12)$. Reduction of EELV has been confirmed by CT scan in healthy patients (13) and by wash-out/wash-in method in both healthy and obese patients (14). Investigations of physiological changes occurring during the period of extraperitoneal $\mathrm{CO}_{2}$ insufflation mostly focused on blood gas changes. Extraperitoneal insufflation has been reported to increase arterial $\mathrm{pCO}_{2}$, with data suggesting a more rapid and greater total increase in End-tidal $\mathrm{CO}_{2}\left(\mathrm{ETCO}_{2}\right)$ during extraperitoneal insufflation than pneumoperitoneum $(7,14)$. In this pilot study, we demonstrated that extraperitoneal insufflation worsened respiratory mechanics and decreased thoracopulmonary compliance and FRC. We may postulate that extraperitoneal insufflation effects are similar to pneumoperitoneum effects as increase of abdominal cavity pressure and cranial movement of diaphragm. CT-scan study performed during extraperitoneal insufflation would help understanding the mechanisms, as previously published in pneumoperitoneum (7). Moreover, it would be interesting to evaluate the magnitude of extraperitoneal insufflation respiratory effects by comparing respiratory mechanics during extraperitoneal and intraperitoneal insufflation. In mechanically ventilated patients, EIT study showed that ventilation remained distributed mainly to ventral region (14). Our results at baseline are concordant with these results. The misalignment of ventilation during anesthesia is probably due to atelectasis formation in dorsal lung areas. This concept has been described fifty years ago (15). It has been visualized more recently in the study of Andersson et al. which described dorsal atelectasis by CT scan in patients mechanically ventilated after several minutes of stable anesthesia (7). We can expect that extraperitoneal insuf- flation may also lead to such atelectasis as suggested by the decrease in EELV we observed. However, CT scan studies as performed by Anderson et al. would be interesting to visualize atelectasis formation after extraperitoneal insufflation (7). To date, the impact of extraperitoneal insufflation on ventilation distribution is not known. Recently, the effect of PEEP and intraperitoneal insufflation on regional ventilation during laparoscopic surgery was studied by EIT (14). This study showed that effects of pneumoperitoneum on ventilation distribution were depending on the application of PEEP or not before pneumoperitoneum induction. In the ZEEP group, the authors found a lower ventral shift of ventilation after pneumoperitoneum, whereas in $10 \mathrm{cmH}_{2} \mathrm{O}$ PEEP group, they observed a higher ventral shift. In our study, we observed a dorsal shift of ventilation distribution after $10 \mathrm{cmH} 20$ PEEP application. The ventral shift of ventilation during anesthesia is likely due to the occurrence of dorsal atelectasis. We may postulate that $10 \mathrm{cmH}_{2} \mathrm{O}$ PEEP application led to alveolar recruitment and decreased dorsal atelectasis, leading to a higher amount of ventilation in dorsal zones. The increase in arterial pressure observed after insufflation is concordant with previously published data $(2,4)$. The raise of $\mathrm{EtCO}_{2}$ observed has also been described in other studies (4). Our study had several limitations. First, it was only a pilot study with a small number of patients. Clinical relevance of our results can be questioned. Second, EIT is a noninvasive, radiation-free tool to assess regional lung ventilation at the bedside and the operating room. It is able to detect dynamically regional changes of ventilation during mechanical ventilation (14, $16,17)$. However, EIT is a focal monitoring of ventilation and not a global monitoring of ventilation. The results of impedance changes provided by the device concerned a cross sectional section of the lung, depending on the location of the belt. In our study, the results of impedance changes we published are reliable with lower lung regions, and not upper lung regions. It could be interesting to design the same study with two belts locations, in the upper and lower regions. Another limitation was the inability of EIT to perform measures when electrocauter is on, because device switched to safety mode. Third, our study protocol stopped 15 minutes after pneumoperitoneum induction and started before the operation. It is hard to postulate on the effect of extraperitoneal insufflation on ventilation distribution during the operation and after it. However, Karsten et al. studied the effects of pneumoperitoneum during the operation, and the shift in ventilation distribution observed at the beginning of insufflation remained constant throughout the procedure (14). Finally, changes in respiratory functions may be also influenced by preoperative positions. According to our protocol, measurements were performed in neutral dorsal decubitus. During laparoscopic surgical procedures, patients may be in slight head-down position, and pressure of abdominal contents on the diaphragm is likely to cause a higher decrease in thoracopulmonary 
compliance, and FRC. In conclusion, the current study showed that extraperitoneal insufflation worsens respiratory mechanics, as previously described in intraperitoneal insufflation. Application of $10 \mathrm{cmH}_{2} \mathrm{O}$ PEEP increased FRC and led to homogenization of ventilation distribution. These preliminary results may justify other studies with a greater number of patients to evaluate the clinical impact of respiratory changes during $\mathrm{CO}_{2}$ extraperitoneal insufflation.

\section{Acknowledgements}

The authors thank the anesthesia team of Laveran Military Teaching Hospital, in Marseille, for their technical assistance. Julien Bordes and Cecilia Mazzeo are to be considered co-first authors.

\section{References}

1. Cavazzola LT, Rosen MJ. Laparoscopic versus open inguinal hernia repair. Surg Clin North Am. 2013;93(5):1269-79.

2. Wright DM, Serpell MG, Baxter JN, O'Dwyer PJ. Effect of extraperitoneal carbon dioxide insufflation on intraoperative blood gas and hemodynamic changes. Surg Endosc. 1995;9(11):1169-72.

3. Mullett CE, Viale JP, Sagnard PE, Miellet CC, Ruynat LG, Counioux $\mathrm{HC}$, et al. Pulmonary $\mathrm{CO} 2$ elimination during surgical procedures using intra- or extraperitoneal $\mathrm{CO} 2$ insufflation. Anesth Analg. 1993;76(3):622-6.

4. Meininger D, Byhahn C, Wolfram M, Mierdl S, Kessler P, Westphal K. Prolonged intraperitoneal versus extraperitoneal insufflation of carbon dioxide in patients undergoing totally endoscopic robotassisted radical prostatectomy. Surg Endosc. 2004;18(5):829-33.

5. Maracaja-Neto LF, Vercosa N, Roncally AC, Giannella A, Bozza FA, Lessa MA. Beneficial effects of high positive end-expiratory pressure in lung respiratory mechanics during laparoscopic surgery. Acta Anaesthesiol Scand. 2009;53(2):210-7.

6. Pelosi P, Foti G, Cereda M, Vicardi P, Gattinoni L. Effects of carbon dioxide insufflation for laparoscopic cholecystectomy on the respiratory system. Anaesthesia. 1996;51(8):744-9.

7. Andersson LE, Baath M, Thorne A, Aspelin P, Odeberg-Wernerman
S. Effect of carbon dioxide pneumoperitoneum on development of atelectasis during anesthesia, examined by spiral computed tomography. Anesthesiology. 2005;102(2):293-9.

8. Heinze H, Eichler W. Measurements of functional residual capacity during intensive care treatment: the technical aspects and its possible clinical applications. Acta Anaesthesiol Scand. 2009;53(9):1121-30.

9. Bikker IG, Scohy TV, Ad J, Bakker J, Gommers D. Measurement of end-expiratory lung volume in intubated children without interruption of mechanical ventilation. Intensive Care Med. 2009;35(10):1749-53.

10. Gunnarsson L, Strandberg A, Brismar B, Tokics L, Lundquist H, Hedenstierna G. Atelectasis and gas exchange impairment during enflurane/nitrous oxide anaesthesia. Acta Anaesthesiol Scand. 1989;33(8):629-37.

11. Brismar B, Hedenstierna G, Lundquist H, Strandberg A, Svensson L, Tokics L. Pulmonary densities during anesthesia with muscular relaxation--a proposal of atelectasis. Anesthesiology. 1985;62(4):422-8.

12. Hedenstierna G, Strandberg A, Brismar B, Lundquist H, Svensson L, Tokics L. Functional residual capacity, thoracoabdominal dimensions, and central blood volume during general anesthesia with muscle paralysis and mechanical ventilation. Anesthesiology. 1985;62(3):247-54.

13. Futier E, Constantin JM, Pelosi P, Chanques G, Kwiatkoskwi F, Jaber $S$, et al. Intraoperative recruitment maneuver reverses detrimental pneumoperitoneum-induced respiratory effects in healthy weight and obese patients undergoing laparoscopy. Anesthesiology. 2010;113(6):1310-9.

14. Karsten J, Luepschen H, Grossherr M, Bruch HP, Leonhardt S, Gehring $\mathrm{H}$, et al. Effect of PEEP on regional ventilation during laparoscopic surgery monitored by electrical impedance tomography. Acta Anaesthesiol Scand. 2011;55(7):878-86.

15. Bendixen HH, Hedley-Whyte J, Laver MB. Impaired Oxygenation in Surgical Patients during General Anesthesia with Controlled Ventilation. A Concept of Atelectasis. NEngl J Med.1963;269:991-6.

16. Frerichs I, Hahn G, Golisch W, Kurpitz M, Burchardi H, Hellige G. Monitoring perioperative changes in distribution of pulmonary ventilation by functional electrical impedance tomography. Acta Anaesthesiol Scand.1998;42(6):721-6.

17. Meier T, Luepschen H, Karsten J, Leibecke T, Grossherr M, Gehring $\mathrm{H}$, et al. Assessment of regional lung recruitment and derecruitment during a PEEP trial based on electrical impedance tomography. Intensive Care Med. 2008;34(3):543-50. 